\title{
Naturaleza jurídica
}

del consentimiento informado

a la luz de los modelos

español y brasileño

de protección al paciente*

\section{1 Éfren Paulo Porfírio de Sa lima"}

Resumen: el presente artículo es una revisión bibliográfica de las doctrina y jurisprudencia acerca de la naturaleza jurídica del consentimiento informado y su respectivo encuadre en el selecto rol de los derechos fundamentales, a través del estudio comparativo de los modelos brasileño y español de protección al paciente. El objetivo es demostrar que el consentimiento informado no es directamente un derecho fundamental en cualquiera de los sistemas analizados y que, esencialmente, tutela la libertad y la autodeterminación en materia de salud.

Palabras clave: consentimiento informado, naturaleza jurídica, derechos fundamentales, libertad y autodeterminación.

\section{The Legal Nature of Informed Consent from the Perspective of the Spanish and Brasilian Models of Patient Protection}

Авsтract: The article presented makes a bibliographical and jurisprudential revision about the juridical nature of informed consent and its respective suitability in the selected list of fundamental rights, through the comparative study of the Brazilian and Spanish models of patient protection. The goal is to de-

Fecha de recepción: i.$^{\circ}$ de octubre de 20 I6. Fecha de aceptación: 8 de mayo de 20 I 7. Para citar el artículo: Sá Lima, E., "Naturaleza jurídica del consentimiento informado a la luz de los modelos español y brasileño de protección al paciente", Revista de Derecho Privado, Universidad Externado de Colombia,n. ${ }^{\circ} 32$, enero-juniode 201 7,473-489.DOI:https://doi.org/Io. I860 I/o I 234366.n32.I 6

** Doctorado en Derecho Civil por la Universidad de Salamanca, Salamanca, España. Profesor de Derecho Civil de la Facultad de Derecho de la Universidad Federal del Piauí, Piauí, Brasil. Contacto: efrencordao@ufpi.edu.br y efrencordao@usal.es 
monstrate that the informed consent doesn't directly constitute a fundamental right in both juridical systems analyzed and that the informed consent protects, essentially, freedom and self-determination in health.

KeYwords: Informed consent, legal nature, fundamental rights, freedom and self-determination.

Sumario: i. Planteamiento del tema. II. Estado de la cuestión en el ordenamiento jurídico español. III. Estado de la cuestión en el sistema jurídico brasileño. Iv. Análisis de las diversas posiciones acerca de la relación entre el consentimiento informado y los derechos fundamentales. Conclusiones. Bibliografía.

\section{Planteamiento del tema}

Determinar la naturaleza jurídica del consentimiento informado no constituye una elucubración puramente especulativa, sino que acarrea consecuencias de índole práctica, porque de la naturaleza jurídica del derecho al consentimiento informado depende qué normas sean aplicables ${ }^{\mathrm{I}}$.

El consentimiento informado es esencialmente un derecho del paciente. Consiste en el derecho a ser informado y en el derecho a decidir sobre la ejecución del acto médico. Por consiguiente, el consentimiento informado, como medio de tutela del derecho a la autodeterminación en materia de sanidad, tiene un doble alcance: soberanía de decisión con respecto a la ejecución del acto médico y barrera contra la intromisión no voluntaria que afecte la integridad biopsicosocial del paciente.

La metodología del análisis tendrá en cuenta las similitudes y diferencias de los modelos brasileño y español de protección al paciente, mediante una revisión bibliográfica de la doctrina y la jurisprudencia acerca de la naturaleza jurídica del consentimiento informado. El objetivo es demostrar que el consentimiento informado no es directamente un derecho fundamental en cualquiera de los sistemas analizados y que, esencialmente, tutela la libertad y la autodeterminación en materia de salud.

\section{Estado de la cuestión en el ordenamiento jurídico español}

En España, la tutela de la autodeterminación en materia de salud, objeto de la Ley 4I/2002, de I4 de noviembre (en adelante, LDP) ${ }^{2}$, orienta la discusión acerca

I Ver García Lerena, V. M. Una concepción iusfundamental del consentimiento informado: la integridad física en investigación y medicina, Oviedo, Junta General del Principado de Asturias et al., 2OI 2, $5 \mathrm{I}$.

2 Ver España. Ley 4I/2002, de I4 de noviembre. Madrid, BOE n. ${ }^{\circ}$ 74, de I 5/I I/2002, 4O I $26 / 40$ I 32. 
de la naturaleza jurídica del consentimiento informado 3 . El debate se centra en determinar la base constitucional en que se asienta el derecho a la autodeterminación en el ámbito de la salud, a saber: el derecho a la integridad física y moral (art. I 5), a la libertad y autodeterminación (art. 9.2), al respeto de la dignidad (art. IO.I) y a la protección de la salud (art. 4I). En este contexto, investigar sobre la naturaleza del consentimiento informado significa responder a la siguiente cuestión: ¿es un derecho fundamental el derecho a la autodeterminación en materia de salud4?

Son fundamentales, en España, los derechos con protección constitucional reforzada 5 . Los refuerzos jurídicos concedidos a la tutela de los derechos fundamentales son de tres órdenes. En primer lugar, son reservadas a la ley orgánica las materias que se refieren a la restricción, promoción, reglamentación y desarrollo de los derechos fundamentales, y para la aprobación de ley orgánica la Constitución exige mayoría absoluta del Congreso. El segundo refuerzo recae en el logro de la exigibilidad directa, o sea, aunque pendiente de reglamentación o desarrollo, la eficacia inmediata o directa de los derechos fundamentales, vinculando a los poderes públicos y privados ${ }^{6}$. Por fin, el recurso de amparo se constituye en una medida judicial que puede ser empleada exclusivamente en la protección de derechos fundamentales ${ }^{7}$. Díez-Picazo ${ }^{8}$ señala las características del recurso de amparo: se trata de una medida judicial que puede ser empleada exclusivamente en la protección de derechos fundamentales, lo que rechaza la posibilidad de su uso para la defensa de otras normas constitucionales o del simple control de legalidad ordinaria. La exclusividad del recurso de amparo como instrumento de protección especial resulta en la inviabilidad del manejo del instrumento contra eventual exceso de protección de los derechos fundamentales, "es decir, quien considera que las normas sobre los derechos fundamentales han sido interpretadas y aplicadas incorrectamente, dando al particular más de lo de-

3 Por todos, Velazco Ramos, C. B. Regulación jurídica del deber de información previa al consentimiento en el aborto, tesis de doctorado, Pedro de Vega García, Consuelo Martínez-Sicluna y Sepúlveda y Ana Llano Torres (dirs.), Universidad Complutense de Madrid, Facultad de Derecho, 2013, I29.

4 Para González León el consentimiento informado se encuentra incluido en el contenido esencial del derecho a la integridad física y moral. Ver González León, Carmen. "La protección del paciente y el consentimiento informado", en Separata de Lex Medicinae - Revista Portuguesa de Direito da Saúde, año 6, n. ${ }^{\circ}$ I 2, $2009,22$.

5 Ver Díez-Picazo y Ponce de León, Luis. Sistemas de derechos fundamentales. Madrid, Civitas, $2003,58-60$.

6 Ver Díez-Picazo, ob. cit., 58-59.

7 No hay semejante remedio jurídico en Brasil. Para la tutela de derechos fundamentales existe la acción de incumplimiento de precepto fundamental ante la Corte Constitucional. Dicha acción ha sido recientemente introducida por Enmienda a la Constitución n. ${ }^{\circ}$ 3, de i 7/03/93, y desarrollada por la Ley 9882/99, de 3 de diciembre.

8 Ver Díez-Picazo, ob. cit., 90. 
bido, no puede acudir al recurso de amparo para que se corrija la interpretación de derechos fundamentales"9. El último rasgo distintivo reside en la subsidiaridad del instrumento, concebido como garantía adicional y última, "que puede activarse sólo cuando todas las demás no han funcionado adecuadamente"

$\mathrm{Al}$ analizar el tema del encuadre del consentimiento médico informado en el rol de los derechos fundamentales en España, García Llerena ${ }^{\mathrm{II}}$ agrupa las diversas posiciones doctrinarias en dos: a) la de quienes creen que el consentimiento informado es un derecho fundamental per se, y b) la de quienes consideran que el consentimiento informado se encuentra vinculado a un derecho fundamental concreto.

En defensa del encuadre en el selecto rol de los derechos fundamentales, algunas decisiones del Tribunal Supremo (en adelante, TS) ${ }^{\mathrm{I} 2}$ señalan el consentimiento informado como "derecho humano fundamental" '3, a ejemplo del leading case de José Manuel Martínez-Pereda Rodríguez ${ }^{\mathrm{I4}}$ :

El consentimiento informado constituye un derecho humano fundamental, precisamente una de las últimas aportaciones realizada en la teoría de los derechos humanos, consecuencia necesaria o explicación de los clásicos derechos a la vida, a la integridad física y a la libertad de conciencia. Derecho a la libertad personal, a decidir por sí mismo en lo atinente a la propia persona y a la propia vida y consecuencia de la autodisposición sobre el propio cuerpo, regulado por la

9 Ibíd., 9г.

Iо Ibíd., 9г.

I I Ibíd., 55-68.

I 2 Ver España. Tribunal Supremo. Sentencia 447/200 I, de i I de mayo. Pon. Luis Martínez-Calcerrada Gómez. La Ley 3457/200I; España. Tribunal Supremo. Sentencia 784/2003, de 23 de julio. Pon. Luis Martínez-Calcerrada Gómez. La Ley 2835/2003.

I3 La expresión derecho bumano fundamental también es utilizada por González León (ob. cit., I8-I9). Se distinguen derechos humanos, libertades públicas y derechos fundamentales. Derechos humanos son la vestimenta transnacional de ciertos derechos de la persona, con cuna en tratados y convenciones internacionales. Libertades públicas son los derechos fundamentales con eficacia vertical, es decir, derechos fundamentales que se ejerce ante el Estado. La expresión "derecho humano fundamental" puede tener dos significados. Como referencia al derecho fundamental exclusivo de lo seres humanos, o solo para realzar el carácter de derecho fundamental con origen en tratados y convenciones internacionales. Atendiendo a que el consentimiento informado no es considerado un derecho fundamental, la expresión "derecho humano fundamental" debe ser reservada a los casos de derechos fundamentales exclusivos de los seres humanos y no de todas las personas. Esta, además, es la posición defendida por Martínez-Pereda cuando escribe: "Se trata, en suma, de un derecho a la libertad personal, a decidir por sí mismo en lo atinente a la propia persona y a la propia vida; en definitiva, a la autarquía personal y a la toma de decisiones personales. Pero se ha expresado quizás mejor, cuando se ha afirmado que estamos ante un derecho humano, porque constituye una consecuencia de la autodisposición sobre el propio cuerpo": Martínez-Pereda Rodríguez, José Manuel. "Algunos efectos producidos por la implantación del consentimiento informado en España", La Ley 6524, 2006, 5).

I4 Ver España. sts 3/200 I, de I 2 de enero. Pon. José Manuel Martínez-Pereda Rodríguez. La Ley I $255 / 200$ I. 
Ley General de Sanidad y actualmente también por el Convenio Internacional para la Protección de los Derechos Humanos y la Dignidad del Ser Humano con respecto a las Aplicaciones de la Biología y de la Medicina y que ha pasado a ser derecho interno español por su publicación en el BOE y forma parte de la actuación sanitaria practicada con seres libres y autónomos.

Conforme se puede leer, al señalar la naturaleza de derecho humano fundamental, el TS ${ }^{15}$ hace referencia a los "clásicos derechos a la vida, a la integridad física y a la libertad de consciencia", con especial realce al "derecho a la libertad personal, a decidir por sí mismo en lo que atañe a la propia persona y a la propia vida, y en consecuencia a la disposición sobre el propio cuerpo". Para Martínez-Pereda Rodríguez, el encuadre correcto del consentimiento informado consiste en considerarlo incluido en la lista de los derechos fundamentales de primer grado $^{16}$, como "una peculiar manifestación del derecho a la libertad y a la dignidad de la persona humana [...], en suma, un derecho a la libertad personal, a decidir por sí mismo en lo que atañe a la propia persona y a la propia vida" ${ }^{17}$.

Simón Lorda ${ }^{18}$ argumenta que entre los cuatro valores superiores del ordenamiento jurídico español: libertad, justicia, igualdad y pluralismo político, el consentimiento informado se encuentra íntimamente vinculado a la libertad, ya que la exigencia del consentimiento del paciente para la práctica del acto médico presupone el reconocimiento de que las decisiones relativas a la intervención en el cuerpo humano pertenecen al ámbito de la libertad de la propia persona. El núcleo esencial del consentimiento informado "reside en la defensa de la libertad personal, entendida en este caso[,] más que como mera libertad de movimientos (art. I 7. CE) o mera libertad ideológica (art. I6 CE) -que también-, como libre desarrollo de la personalidad (art. ı. I CE)”. Según el autor, en razón de que el acto médico afecta al propio cuerpo de una persona, cualquier intervención en la esfera corporal depende de su libre aceptación, "a la luz de la escala de valores y preferencias que estructuran su propia personalidad" 19 .

I 5 De acuerdo con García Llerena, ob. cit., 57, el TS en estas manifestaciones refleja la original doctrina de García Guillén y seguida, entre otros, por De Lorenzo y Montero y Marín Gámez y Galán Cortés.

i6 La referencia a los derechos fundamentales de primera generación aparece en el texto como respuesta a la posición defendida por Marín Gámez, para quien el consentimiento informado debe ser encuadrado en el rol de los derechos sociales. Ver Marín Gámez, José Ángel. "A vueltas con la constitucionalidad del artículo io.6 de la Ley General de Sanidad: la relevancia jurídica del consentimiento informado", Revista General de Derecho, n. o 6ro/6r I, I995, 8237$8257)$.

I 7 Ver ob. cit., 5 .

i 8 Ver Simón Londa, P. El consentimiento informado: bistoria, teoría y práctica, Madrid, Triacastela, 2000.

I9 Ver ob. cit., I 78-г 80. 
Para López Sánchez ${ }^{20}$, los derechos del paciente constituyen una concreción de los derechos humanos, atribuidos a la persona, aunque enferma, a mantener su autonomía personal y su capacidad de autorrealización. La autora argumenta que el derecho a la información proviene del derecho a la autodisposición del propio cuerpo, pertinente a todos, y concierne "al ámbito de su libertad, en la medida en que, sólo si se conocen los aspectos vertebrales de la enfermedad, se puede tomar una decisión consciente" ${ }^{2 \mathrm{I}}$.

$\mathrm{Al}$ sostener la naturaleza de derecho fundamental, Sánchez Rubio ${ }^{22}$ subraya la esencia del consentimiento informado en el derecho a la información. En este paso, destaca la consagración del derecho a la información en el rol de los derechos fundamentales del sistema jurídico español, con aplicación directa en el campo de la sanidad y, en especial, del consentimiento informado. Señala la autora $^{23}$ que el consentimiento informado se constituye en derecho humano fundamental como consecuencia de su vinculación a los derechos a la vida, a la integridad física y a la libertad de consciencia ${ }^{24}$.

Otros autores defienden el encuadre del consentimiento informado en el rol de los derechos sociales, como Marín Gámez²5, según el cual el consentimiento informado debe obedecer a la clasificación derivada del grupo de los derechos sociales, "puesto que para hablar de consentimiento informado se ha de dar como necesario presupuesto un tipo de sistema político que, siendo democrático, haya sido alumbrado por la fórmula más evolucionada de la última o reciente generación de derechos". Añade que los derechos de primera generación son siempre derechos negativos opuestos en virtud del Estado, mientras que el consentimiento informado, en el contexto sociosanitario, representa el desprendimiento de la inercia de una sociedad liberal ${ }^{26}$.

\section{Estado de la cuestión en el sistema jurídico brasileño}

El debate doctrinal que se planteó en España respecto a si el consentimiento informado es un derecho fundamental no encuentra resonancia en el sistema

Ver López Sánchez, C. Testamento vital y voluntad del paciente. Madrid: Dykinson, 2003, 20, en especial el argumento desarrollado en la nota de rodapié n. ${ }^{\circ} 23$.

I Ver ob. cit., 20.

SÁnchez Rubio, M. A. Marco jurídico del derecho a la información en las relaciones sanitarias: especial consideración del consentimiento informado, 2007, tesis de doctorado en Derecho, Universidad de Extremadura, Cáceres, 2007, I 5.

3 Ver ob. cit., 473.

Ver ob. cit., 204 .

Ver Marín Gámez, ob. cit., 8237-8257.

Objeta Martínez-Pereda Rodríguez que Marín Gámez confunde el desarrollo social y la ampliación de los beneficios asistenciales y tecnológicos a toda sociedad civil con consentimiento informado (ver ob. cit., 5). 
brasileño de protección al paciente. El tema no es tratado de forma sistemática entre los autores, sino tangencialmente. En este sentido, pueden agruparse las diversas manifestaciones ${ }^{27}$ de la siguiente manera: los que lo consideran atado directamente al principio de la dignidad de la persona humana; los que creen que está vinculado a algún derecho fundamental; los que estiman que es un derecho derivado de derechos de la personalidad y, por último, los que defienden que el consentimiento está fundamentado en el derecho a la información como consecuencia de la buena fe objetiva.

Para los que señalan la dignidad de la persona humana como fundamento jurídico del consentimiento informado ${ }^{28}$, la base de su argumentación reside en la idea de que el hombre, dotado de libertad, es un fin en sí mismo, y que es el derecho el que debe tutelar sus legítimos intereses. En la condición de unidad biopsicosocial, la tutela y promoción de la persona humana, en la vida civil brasileña, pasa al estatus de cláusula general (art. I. ${ }^{\circ}$, inc. III Constitución Federal, en adelante CF), imponiendo la realización eficaz del libre desarrollo de la personalidad como actuación positiva en la tutela de las situaciones jurídicas existenciales ${ }^{29}$.

En ese paso, según Clotet $^{30}$, por el hecho de tutelar la autonomía, la libertad y el respeto de las personas, el consentimiento informado constituye un derecho fundamental "del ser humano, de carácter inviolable, incluso en el ejercicio de la medicina o de la experimentación con seres humanos". A su turno, Joppert Ragazzo conecta el consentimiento informado indirectamente con el principio de la dignidad de la persona humana y directamente con el derecho fundamental a la salud ${ }^{3}$.

27 De forma aislada, otros fundamentos son indicados respecto de la naturaleza jurídica del consentimiento informado. Entre otros, Menezes de Simão Kuhn encuadra la naturaleza jurídica del consentimiento como regla ética, vinculada a los derechos humanos. Ver Menezes de SIмão KuHN, A. Os limites do dever de informar do médico e o nexo causal na responsabilidade civil na jurisprudência brasileira. 2009, disertación de maestría en Derecho, Universidade Federal do Rio Grande do Sul, Porto Alegre, 2009, 52). Aunque no justifique su afirmativa, Branco indica la naturaleza jurídica del consentimiento informado en el abuso de derecho. Ver Carlos Branco, G. L. "Aspectos da responsabilidade civil e do dano médico", Revista do Tribunais, n. ${ }^{\circ}$ 733, I996, I 2.

28 Ver Villaça de Azevedo, Á. "Autonomia do paciente e direito de escolha de tratamento médico sem transfusão de sangue”, en Villaça De Azevedo, Á. y Ricardo Ligiera, W. (coords.). Direito dos pacientes, São Paulo, Saraiva, 2O I 2, 272). En la misma línea, Ricardo Ligiera, Wilson. "Termo de consentimento informado ou de 'constrangimento desinformado'? - A defesa do paciente ante uma medicina ilícita e antiética”, en ibíd., 625-626.

29 Vencelau Meireles denomina el derecho a la autodeterminación en materia de sanidad, a ejemplo del consentimiento informado, como "autonomía existencial”, es decir, "el poder jurídico para la autoreglamentación de intereses existenciales". Ver Vencelau Meireles, R. M. "Negócios biojurídicos", en Brochado Teixeira, A. C. y Dadalto, A. (coords.). Dos hospitais aos tribunais. Belo Horizonte: Del Rey, $2013,623$.

30 Ver Clotet, J. “O consentimento informado nos Comitês de Ética em Pesquisa e na prática médica: conceituação, origens e atualidade", Revista Bioética, Brasília, vol. 3, n. ․ I, 2009.

3 I Ver Joppert Ragazzo, C. E. O dever de informar dos médicos e o consentimento informado. Curitiba: Juruá, 2006, 57-59. 
En su análisis acerca de la recusación de tratamiento médico por objeción de consciencia, Nery Júnior ${ }^{22}$ considera al consentimiento informado "expresión de la libertad de autodeterminación, libertad garantizada como derecho constitucional fundamental, previsto en el artículo $5 .^{\circ}$, capítulos iı y III, de la CF/ı 988. El consentimiento informado, más que un derecho fundamental autónomo, es instituto cuya finalidad es conferir a estos derechos la fuerza que les es propia”.

El derecho fundamental a la información del paciente-consumidor encuentra amparo ora en el artículo $5 .^{\circ}$, xxxiI, CF, ora en el respeto a la libertad ${ }^{33}$. En razón de esta previsión constitucional, Lima Marques ${ }^{34}$ sostiene que el consentimiento informado tiene naturaleza de derecho fundamental. Al conferirle un estatus de derecho fundamental, la citada autora 35 realza que la violación de los deberes informativos genera un daño autónomo a la libertad ${ }^{36}$ y al derecho de elección, pues el respeto a la dignidad y autonomía de voluntad del paciente, exigido por la Constitución y desarrollado en la legislación ordinaria por el Código de la Defensa del Consumidor (en adelante, CDC), se constituye en el tonificador del consentimiento informado.

Según Cavalieri Filho, el consentimiento informado es un derecho de la personalidad, ya que el bien jurídico tutelado es la inviolabilidad del cuerpo, encontrando base normativa en el art'́culo i 5 del nuevo código civil (en adelante, NCC), a contrario sensu ${ }^{37}$. Nubens Barbosa Miragem ${ }^{3}$ se refiere a la buena fe objetiva como base o fundamento del consentimiento informado. Sostiene que el deber de información y esclarecimiento se encuentra debidamente positivado

32 Ver Nery Júnior, N. "Direito de liberdade e recusa de tratamento por motivo religioso", Revista de Direito Privado, vol. 4I, $2010,223$.

33 Ver Lusa Cadore Weber, M. R. "Responsabilidade civil do médico", Revista de Direito Privado, n. ${ }^{\circ}$ I $8,2004,4$.

34 Ver Lima Marques, C. "A responsabilidade dos médicos e do hospital por falha no dever de informar ao consumidor", Revista dos Tribunais, n. ${ }^{\circ} 82$ 7, 2004, I 2.

35 Ver ob. cit., 9.

36 Santos Carraro aduce que el consentimiento informado "puede ser fundamentado por el principio básico del respeto por la persona en sus valores fundamentales [...] [con] base en la Constitución Federal (CF), en el Código Civil (CC) y en el sistema jurídico vigente, en lo que concierne al reconocimiento del principio fundamental de la autonomía de la persona": Santos Carraro, A. "O uso do termo de consentimento informado como forma de verificação da responsabilidade civil por parte do cirurgião-dentista", tesis de Doctorado en Ciencias Odontológicas, Universidade de São Paulo, 20 Iо, I 7. Ênio Santarelli Zuliani insiere el consentimiento informado como derecho a la libertad personal, pues consentir significa autorizar. Ver Santarelli Zuliani, E. "Omissão de socorro médico e sigilo médico", en Tavares Da Silva, R. B. (coord.). Responsabilidade civil: responsabilidade civil na área da saúde. 2. a ed., Rio de Janeiro, Saraiva-FGV, 2009, I83.

37 Ver Cavalieri Filho, S. Programa de responsabilidade civil. 8. a ed., São Paulo: Atlas, 2008, 377.

38 Ver Nubens Barbosa Miragem, B. Responsabilidade civil médica no direito brasileiro, Revista de Direito do Consumidor, vol. 63, 2007, 61. 
en el sistema jurídico brasileño en las reglas del $\operatorname{CDC}^{39}$ y del $\mathrm{NCC}^{40}$. En el mismo camino, Ramos Filho ${ }^{4}$ señala el artículo $6 .^{\circ}$, III, CDC como fundamento del consentimiento informado en el derecho brasileño.

\section{Análisis de las diversas posiciones acerca de la relación entre el consentimiento informado y los derechos fundamentales}

El Tribunal Constitucional de España (en adelante, TC), en decisión de 20 I I, conoció y juzgó procedente el recurso de amparo para declarar la vulneración del derecho fundamental a la integridad física de un paciente que, tras haberse sometido a cateterismo cardíaco, perdió la funcionalidad de la mano derecha, sin que le hubieran sido facilitadas informaciones previas sobre posibles riesgos y alternativas de tratamiento. Según el TC en dicho fallo ${ }^{42}$, "el consentimiento del paciente a cualquier intervención sobre su persona es algo inherente, entre otros, a su derecho fundamental a la integridad física, a la facultad que este supone de impedir toda intervención no consentida sobre el propio cuerpo, que no puede verse limitada de manera injustificada como consecuencia de una situación de enfermedad".

La importancia de esta manifestación está en el hecho de que, por primera vez, el TC reconozca que el consentimiento informado es algo que proviene directamente del derecho fundamental a la integridad física, siguiendo una posición consolidada en la Corte según la cual la protección del artículo i 7. I está dirigida a la "libertad física" 43 . Como se percibe, el propio TC no alza directamente el consentimiento al plano de derecho fundamental, apenas lo vincula al derecho a la integridad física 44 .

CDC, arts. $6^{\circ}, 3 \mathrm{I}, 46$ y $5 \mathrm{I}$.

40 NCC, arts. I I 3, I 87 y 422.

4I Ver Ramos Filho, I. "Elementos do contrato médico", Revista de Direito Privado, n. ${ }^{\circ}$ 7, 200 , 6.

42 Ver España. Tribunal Constitucional. Sentencia n. ${ }^{\circ} 37-20$ I I, de 28 de marzo. Pon. Elisa Pérez Vera. La Ley I 4I 99-20 I I. I). En el mismo sentido, Sentencia n. ${ }^{\circ}$ I 20-I 990, de 27 de junio, Pon. Fernando García-Mon y González Regueral, La Ley i 76 I-JF/oooo; y Sentencia n. o 207/ı 996 , de 6 de diciembre, Pon. Vicente Gimeno Sendra, La Ley I 527-I 997.

43 Sobre la importancia de la Sentencia n. ${ }^{\circ} 37$, de 20 i i, del TC, consultar, por todos, Pelayo González-Torre, A. "El consentimiento informado en sentencia del Tribunal Constitucional Español 37/20I I de 28 de marzo", Cuadernos Iberoamericanos de Derecho Sanitario, vol. 2, n. ${ }^{2}$, $766-785$.

44 Según Guerra Vaquero, "la novedad radica en la originalidad del pronunciamiento relativo a que la privación de información equivale a una privación o limitación del derecho a consentir o rechazar una actuación médica determinada, inherente al derecho fundamental a la integridad física y moral": Guerra VAquero, A. Y. "Una perspectiva constitucional sobre bioética: la figura del consentimiento informado del paciente", Revista Digital Facultad de Derecho, n. ${ }^{\circ}$ 5, 20 I 2, 34. 
Además, la mayoría de la doctrina española 45 es contraria a considerar que el consentimiento informado es un derecho fundamental, y esta idea se apoya en dos argumentos sólidos, surgidos a lo largo de los debates parlamentarios y conectados al principio de la reserva legal. En primer lugar, se alega que el consentimiento informado no es derecho fundamental porque esta institución fue legislativamente desarrollada mediante una ley ordinaria y, si hubiese sido un derecho fundamental, su desarrollo se tendría que haber realizado por medio de una ley orgánica. En segundo lugar, no se puede olvidar que el consentimiento informado no consta expresamente entre los derechos fundamentales de los artículos ig a $29 \mathrm{CE}^{4}$.

En el ordenamiento jurídico español, la LDP tiene estatus de norma básica y se ha tramitado como ley ordinaria, y estas características de norma básica y ley ordinaria no son las que se exigen para el desarrollo de los derechos fundamentales de la CE. La posibilidad de legislarse sobre la autonomía del paciente por medio de ley ordinaria, la competencia concurrente de las comunidades autónomas y la no presencia en la lista de los derechos fundamentales de los artículos I4 a $29 \mathrm{CE}$ confieren jerarquía común al consentimiento informado47.

Domínguez Luemo ${ }^{8}$ añade que la opción de regulación por medio de ley ordinaria atendió al criterio del TC, conforme el cual es reservado a la ley orgánica el desarrollo directo, en el orden infraconstitucional, de los derechos fundamentales y de las libertades públicas. Dicho de otro modo: al estar legislado por medio de ley ordinaria, el consentimiento informado no desarrolla los derechos fundamentales. En este contexto, son fundamentales solamente los derechos a la integridad física y moral y el derecho a la libertad y autodeterminación 49 .

45 Conforme señala González León, la mayoría de la doctrina entiende que "el consentimiento informado no se puede calificar como "derecho humano fundamental"': ob. cit., i 8. En el mismo sentido, Domínguez Luelmo, A. Derecho sanitario y responsabilidad médica, 2. a ed., Valladolid, Lex Nova, 2007, 50-5 I.

46 Gros Espiel señala dos posibles causas para la no inclusión del consentimiento informado como derecho fundamental en la Constitución española: el carácter reciente de la bioética, que explicaría su ausencia inicial, y la polémica alrededor de los temas de la bioética, que resultaría en la dificultad de alcanzar el consenso necesario para introducir el consentimiento informado en el texto constitucional. Ver Gros Espiell, Héctor, "Constitución y bioética”, en Romeo CasaboNA, C. M. (coord.), Derecho biomédico y bioética, Comares, Granada, I998, I37-I 5 O.

47 Ver Parra Lucán, M. á Á. "La capacidad del paciente para prestar válido consentimiento informado. El confuso panorama legislativo español", Aranzadi Civil, n. ${ }^{\circ}$ I, 2003, I904.

48 Conforme el autor, "[1] as dudas se planteaban por considerar que la regulación afectaba a derechos fundamentales, aunque acertadamente a mi juicio se tuvo en cuenta el criterio del Tribunal Constitucional de no extender la previsión del artículo 8I. I de la Constitución a cualquier desarrollo indirecto de los derechos fundamentales": ob. cit., 50.

49 Sobre este aspecto, De Lorenzo y Sancho Caro señalan que en la relación médico-paciente el consentimiento informado encuentra su fundamento en la dignidad y en la libertad de la persona. Ver De Lorenzo y Sánchez Caro, "Consentimiento informado”, en Gómez y DíazCastroverde, J. M.; Sanz Larruga, J. y Juane Sánchez, M. (coords.), Lecciones de derecho sanitario. A Coruña, Universidad da Coruña, I999, 2 Io. 
A propósito, la conclusión de De Lorenzo y Sanches Caro ${ }^{\circ}$ es semejante cuando afirman que "el consentimiento informado es, por tanto, la justificación del acto médico, basado en el derecho del paciente a su autonomía o autodeterminación”. En este sentido, es de advertir, con De las Heras García5 ${ }^{\mathrm{I}}$, que la posibilidad del paciente de renunciar previamente a la información, en sede de consentimiento informado, maltrata una de las principales características de los derechos fundamentales, que es exactamente la de la irrenunciabilidad de derechos de estos jaeces, conforme afirma el autor:

Si admitimos que el deber de información y el consentimiento, como venimos reconociendo, derivan de un mismo tronco y se hallan fuertemente conectados entre sí, cabe dejar sentado que la renuncia expresa a la previa información conllevaría asimismo la renuncia a prestar el consentimiento (en otras palabras, si no quiero informarme es que no quiero consentir informadamente), lo que equivaldría entonces -siguiendo tal teoría- a renunciar nada menos que a un derecho humano o fundamental negando a este último, de entrada, uno de los rasgos que lo caracterizan.

Abordada esta cuestión preliminar, atinente al sistema español de protección al paciente, se hacen necesarias dos observaciones comunes al derecho brasileño e hispánico. El consentimiento informado no es señalado directamente como derecho fundamental, solo indirectamente, siendo derechos fundamentales únicamente los intereses alcanzados por el consentimiento informado. Nos queda, por lo tanto, señalar si el consentimiento informado está dirigido, esencialmente, a la tutela de la información o de la libertad (autodeterminación).

Entiendo que la información no es indicada como esencia del consentimiento informado. La información integra el núcleo básico del consentimiento informado. Sin embargo, la correlación derecho-deber de información, a nuestro juicio, no supone la esencia del instituto. Destacamos dos motivos que sirven para rechazar la idea del derecho a la información como esencia del consentimiento informado. El primero, concerniente a su construcción histórica. El segundo, referido a que la función del consentimiento informado desplaza la esencia del instituto del derecho a la información hacia el derecho a la autodeterminación.

En su curso histórico, las primeras manifestaciones de la teoría del consentimiento informado están vinculadas a la idea de protección a la persona frente a intromisiones indebidas en su cuerpo físico o en su ámbito moral, por medio del reconocimiento a la libertad de decidir acerca de la práctica del acto que afecte a su propio cuerpo.

50 Ver ob. cit., 2 I 2.

5 I Ver ob. cit., 2398-2399. 
Funcionalmente, es la información la que sirve al consentimiento y no el consentimiento el que se encuentra al servicio de la información. En el consentimiento informado, la información es el medio y el asentimiento libre y soberano su fin $5^{2}$. Los deberes informativos son impuestos al médico ante la asimetría de poder que existe en la relación de sanidad, asimetría que reside exactamente en la desigualdad que existe acerca de la información necesaria para la toma de decisión ${ }^{53}$. Según Fernández Gimeno ${ }^{54}$, la desigualdad de conocimientos entre profesional (médico) y no-profesional (paciente) proviene de la complejidad de las intervenciones profesionales, del alto grado de especialización que las mismas requieren y de la dificultad de comprensión de los objetos o negocios que son atendidos por estos profesionales. De ello resulta que el paciente "se ponga literalmente en manos de los mismos y les entregue su destino, su vida, su libertad y su hacienda" 55 .

La función de la información, en el consentimiento informado, es esclarecer al paciente para que pueda decidir acerca de la práctica del acto de salud que se le propone. De tal modo que, en virtud de esta función del consentimiento informado, la esencia se desplaza del derecho a la información hacia el derecho a la autodeterminación. En este sentido, Bermejo Merino ${ }^{5}$ advierte que el consentimiento informado no se restringe al derecho a la información, sino que se extiende "a las condiciones que deben ser cumplidas" para respetar el derecho del paciente a la toma de "decisiones sobre lo que se ha hecho con su salud y con su cuerpo, y para ello exige información, mas no solo información”. Comparte esta posición Corcoy Bidasolo57, para quien la importancia moderna del consentimiento informado se fundamenta en la "libertad de autodeterminación del sujeto" y recae sobre el paciente, como titular del derecho a decidir soberanamente sobre los riesgos que está dispuesto a asumir en nombre de su bienestar.

52 Para Fernández Fernandes y Haygert Pitha, la información "constituye una etapa para obtener el consentimiento informado, que viene a ser la aceptación del procedimiento terapéutico, propuesto por el médico, por el paciente [sic], después del debido proceso de información, comúnmente denominado proceso de consentimiento informado": Fernández Fernandes, C. y Haygert Pithan, L. "O consentimento informado na assistência médica e o contrato de adesão: uma perspectiva jurídica e bioética”, Revista HCPA - Hospital das Clínicas de Porto Alegre e Faculdade de Medicina da Universidade Federal do Rio Grande do Sul, n. ${ }^{2}$ 7, vol. 2, 2007, 79.

53 Ver Lima Marques, ob. cit., 5.

54 Ver Fernández Gimeno, J. P. "El consentimiento informado en el arrendamiento de servicios. Examen particular del consentimiento informado del acto médico", Noticias de la Unión Europea, n. ${ }^{\circ}$ 2 I 2-2 I 3, 2002, 35-44.

55 Ver ob. cit., 37.

56 Ver Bermejo Merino, C. “Consentimiento informado y ¿derecho a la ignorancia?”, en GómezHeras, J. M. ${ }^{a}$ G. a y Velayos Castelo, C. (coords.), Bioética: perspectivas emergentes y nuevos problemas. Madrid: Tecnos, 2005, 3 I 2.

57 Ver Corcoy Bidasolo, M. "Ética y prioridades en salud y servicios sanitarios", en Cabasés Hita, J. M.; Aibar Remón, C. y Villalbí Hereter, J. R. (coords.). Informe sespas 2002: Invertir para la salud - Prioridades en salud pública, vol. 2, Valencia, Generalitat Valenciana, 2002, 607. 
Es de advertir, con De las Heras García ${ }^{8}$, que la posibilidad del paciente de renunciar previamente a la información, en sede de consentimiento informado, choca con una de las principales características de los derechos fundamentales, que es exactamente la de la irrenunciabilidad de estos derechos.

En nuestra opinión, el consentimiento informado proviene directamente del derecho a la libertad (autodeterminación). En efecto, en materia de derecho penal, como señala Muñoz Conde ${ }^{59}$, una intervención médica exitosa, practicada en los límites de la lex artis, con el restablecimiento de la salud o la simple mejora del paciente, "difícilmente puede considerarse que cumpla los elementos del tipo de un delito de lesiones", aunque viole el consentimiento informado del paciente. Advierte el autor que el consentimiento o no del paciente, ante el tratamiento exitoso, se refiere a "un problema de protección penal a su derecho a la autodeterminación o autonomía y, por lo tanto, como un posible delito contra su libertad, pero nunca como un delito contra su salud, es decir, como un delito de lesiones"6o.

En Brasil, este argumento es compartido por Nery Júnior ${ }^{6 \mathrm{I}}$, al señalar que la práctica del acto médico contra la voluntad expresa del paciente implica un delito contra la libertad individual, capitulado como "constreñimiento ilegal".

Dicho con otras palabras, ante el tratamiento exitoso no hay sanción penal para tutelar el derecho a la información clínica, ni a la integridad física; no obstante, en razón del bien jurídico libertad y autodeterminación, en caso de tratamiento exitoso, es posible encuadrar la violación del deber de obtener el consentimiento en el delito contra la libertad.

\section{Conclusiones}

La tutela del bien jurídico “autodeterminación” en materia de salud demuestra el carácter esencial del consentimiento para la protección de otros bienes jurí$\operatorname{dicos}^{62}$, como la libertad. En refuerzo al derecho a la autodeterminación en materia de salud como núcleo esencial del consentimiento informado, la LDP, en la exposición de motivos, aparta el "derecho a la información" del "consentimiento informado", al afirmar que la Convención de Oviedo "trata explícitamente, con

$5^{8}$ Ver de las Heras García, M. "Recepción y naturaleza del llamado 'consentimiento informado' del paciente”, en González Porras, J. M. y Méndez González, F. P. (coords.). Libro bomenaje al profesor Manuel Albaladejo García, t. I, Murcia, Editum, 2004, 2398-2399.

59 Ver Muñoz Conde, F. "Algunas cuestiones relacionadas con el consentimiento del paciente y el tratamiento médico", en Muñoz Conde, F. (coord.), Problemas actuales del derecho penal y de la criminologia - Estudios penales en memoria de la Profesora Dra. María del Mar Díaz Pita. Valencia: Tirant lo Blanch, 2008, $45 \mathrm{I}$.

60 Ver ob. cit., $45 \mathrm{I}$.

6I Ver Nery Júnior, ob. cit., i 8.

62 Ver Fernández Gimeno, ob. cit., $3^{8 .}$ 
detenimiento y extensión, sobre la necesidad de reconocer los derechos del paciente, entre los cuales [...] el consentimiento informado".

Sea como fuere, la autodeterminación en materia de sanidad constituye la esencia del consentimiento informado, pero en sí el consentimiento informado no es un derecho fundamental, al menos directamente, ni en España ni tampoco en Brasil.

\section{Bibliografía}

Bermejo Merino, C. “Consentimiento informado y ¿derecho a la ignorancia?”, en Gómez-Heras, José M. ${ }^{a}$ G. ${ }^{a}$ y Velayos Castelo, Carmen (coords.), Bioética: perspectivas emergentes y nuevos problemas, Madrid, Tecnos, 2005.

Carlos Branco, G. L. "Aspectos da responsabilidade civil e do dano médico", Revista do Tribunais, n. ${ }^{\circ}$ 733, I996, I-20 (DTR \I996\582).

Cavalieri Filho, S. Programa de responsabilidade civil, 8ª ed., São Paulo, Atlas, 2008.

Clotet, J. "O consentimento informado nos Comitês de Ética em Pesquisa e na prática médica: conceituação, origens e atualidade”, Revista Bioética, Brasília, vol. 3, n. ${ }^{\circ}$ I, 2009, disponible en: http://revistabioetica.cfm.org.br/index. php/revista_bioetica/article/view/430 Consultado el 20/4/20 I 5 .

Corcoy Bidasolo, M. "Ética y prioridades en salud y servicios sanitarios", en Cabasés Hita, J. M.; Aibar Remón, C. y Villalbí Hereter, J. R. (coords.). Informe SESPAS 2002: Invertir para la salud - Prioridades en salud pública, vol. 2, Valencia, Generalitat Valenciana, 2002, 607.

De las Heras García, M. "Recepción y naturaleza del llamado 'consentimiento informado’ del paciente”, en González Porras, J. M. y Méndez González, F. P. (coord.). Libro bomenaje al profesor Manuel Albaladejo García, t. I, Murcia, Editum, 2004, 2379-2399.

De Lorenzo y Sánchez Caro. "Consentimiento informado”, en Gómez y DíazCastroverde, J. M.; Sanz Larruga, Javier y Juane Sánchez, M. (coord.), Lecciones de derecho sanitario, A Coruña, Universidad da Coruña, I 999.

Díez-Picazo y Ponce de León, L. Sistemas de derechos fundamentales, Madrid, Civitas, 2003. 
Domínguez Luelmo, A. Derecho sanitario y responsabilidad médica, 2. ${ }^{\text {a ed., Vallado- }}$ lid, Lex Nova, 2007.

Fernández Fernandes, C. y Haygert Pithan, L. “O consentimento informado na assistência médica e o contrato de adesão: uma perspectiva jurídica e bioética", Revista HCPA - Hospital das Clínicas de Porto Alegre e Faculdade de Medicina da Universidade Federal do Rio Grande do Sul, n. ${ }^{\circ}$ 27, vol. 2, 2007, 78-82.

Fernández Gimeno, J. P. "El consentimiento informado en el arrendamiento de servicios. Examen particular del consentimiento informado del acto médico", Noticias de la Unión Europea, n. ${ }^{2}$ I 2-2 I 3, 2002, 35-44.

García Lerena, V. M. Una concepción iusfundamental del consentimiento informado: la integridad física en investigación y medicina, Oviedo, Junta General del Principado de Asturias et al., 20 I 2.

González León, C. "La protección del paciente y el consentimiento informado", Separata de Lex Medicinae - Revista Portuguesa de Direito da Saúde, año 6, n. ${ }^{\circ}$ I $2,2009$.

Gros Espiell, H. “Constitución y bioética”, en Romeo Casabona, C.M. (coord.), Derecho biomédico y bioética, Granada, Comares, I998, I37-I 5 O.

Guerra Vaquero, A. Y. "Una perspectiva constitucional sobre bioética: la figura del consentimiento informado del paciente", Revista Digital Facultad de Derecho,.$^{\circ} 5$, 201 $2,237-269$.

Joppert Ragazzo, C. E. O dever de informar dos médicos e o consentimento informado, Curitiba, Juruá, 2006.

Lima Marques, C. "A responsabilidade dos médicos e do hospital por falha no dever de informar ao consumidor", Revista dos Tribunais, n. ${ }^{\circ} 827,2004$, I I48.

López Sánchez, C. Testamento vital y voluntad del paciente, Madrid, Dykinson, 2003.

Lusa Cadore Weber, M. R. "Responsabilidade civil do médico", Revista de Direito Privado, n. ${ }^{\circ}$ I 8, 2004, I 44 Ss. (DTR \2004\235). 
Marín Gámez, J. A. "A vueltas con la constitucionalidad del artículo io.6 de la Ley General de Sanidad: la relevancia jurídica del consentimiento informado", Revista General de Derecho, n. ${ }^{\text {os }} 6$ Io-6I I, I995, 8237-8257.

Martínez-Pereda Rodríguez, J. M. "Algunos efectos producidos por la implantación del consentimiento informado en España”, La Ley, n. ${ }^{\circ}$ 6524, 2006, I-I 5 .

Menezes de Simão Kunn, A. Os limites do dever de informar do médico e o nexo causal na responsabilidade civil na jurisprudência brasileira, disertación de maestría en Derecho, Universidade Federal do Rio Grande do Sul, Porto Alegre, 2009.

Muñoz Conde, F. "Algunas cuestiones relacionadas con el consentimiento del paciente y el tratamiento médico", en Muñoz Conde, F. (coord.), Problemas actuales del derecho penal y de la criminologia - Estudios penales en memoria de la Profesora Dra. María del Mar Díaz Pita, Valencia, Tirant lo Blanch, 20o8, 447-478.

Nery Júnior, N. "Direito de liberdade e recusa de tratamento por motivo religioso", Revista de Direito Privado, vol. 4I, 20IO, I-38 (DTR \2010 \59).

Nubens Barbosa Miragem, B. "Responsabilidade civil médica no direito brasileiro", Revista de Direito do Consumidor, vol. 63, 2007, 52-9I.

Parra Lucán, M. á Á. "La capacidad del paciente para prestar válido consentimiento informado. El confuso panorama legislativo español”, Aranzadi Civil, n. ${ }^{\circ}$ I, 2003, I900I-I 930.

Pelayo González-Torre, A. "El consentimiento informado en sentencia del Tribunal Constitucional Español 37-20 I de 28 de marzo", Cuadernos Iberoamericanos de Derecho Sanitario, vol. 2, n. ${ }^{\circ}$, $2013,766-785$.

Ramos Filho, I. "Elementos do contrato médico", Revista de Direito Privado, n. 7, 200I, I-8 (DTR \200I\296).

Ricardo Ligiera, W. "Termo de consentimento informado ou de 'constrangimento desinformado'? - A defesa do paciente ante uma medicina ilícita e antiética”, en Villaça De Azevedo, Á. y Ricardo Ligiera, W. (coords.). Direito dos pacientes, São Paulo, Saraiva, 20 2, 62 5-640. 
Sánchez Rubio, M. A. Marco jurídico del derecho a la información en las relaciones sanitarias: especial consideración del consentimiento informado, tesis de doctorado en Derecho, Universidad de Extremadura, Cáceres, 2007.

Santarelli Zuliani, Ê. "Omissão de socorro médico e sigilo médico", en TavaRES DA Silva, R. B. (coord.). Responsabilidade civil: responsabilidade civil na área da saúde, 2. ${ }^{\mathrm{a}}$ ed., Rio de Janeiro, Saraiva-Fgv, 2009.

Santos Carraro, A. O uso do termo de consentimento informado como forma de verificação da responsabilidade civil por parte do cirurgião-dentista, tesis de doctorado en Ciencias Odontológicas, Universidade de São Paulo, 20 ıo.

Simón LoRda, P. El consentimiento informado: historia, teoría y práctica, Madrid, Triacastela, 2000.

Velazco Ramos, C. B. Regulación jurídica del deber de información previa al consentimiento en el aborto, tesis doctoral, Pedro de Vega García, Consuelo Martínez-Sicluna y Sepúlveda y Ana Llano Torres (dirs.), Universidad Complutense de Madrid, 20I3.

Vencelau Meireles, R. M. "Negócios biojurídicos", en Brochado Teixeira, A. C. y Dadalto, A. (coord.). Dos hospitais aos tribunais, Belo Horizonte, Del Rey, 20I3.

Villaça De Azevedo, Á. "Autonomia do paciente e direito de escolha de tratamento médico sem transfusão de sangue", en Villaça de Azevedo, Á. y Ricardo Ligiera, W. (coords.). Direito dos pacientes, São Paulo, Saraiva, 20 i 2 , $27 \mathrm{I}-3 \mathrm{O}$. 